\title{
Selinexor in combination with standard chemotherapy in patients with advanced or metastatic solid tumors
}

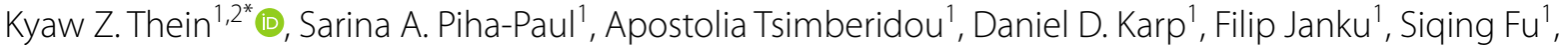

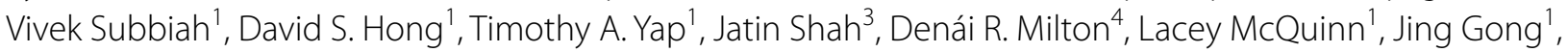 \\ Yanyan Tran', Brett W. Carter ${ }^{5}$, Rivka Colen ${ }^{6}$, Funda Meric-Bernstam ${ }^{1}$ and Aung Naing ${ }^{1}$
}

\begin{abstract}
Selinexor, an oral selective inhibitor of nuclear export (SINE), was demonstrated to hinder the DNA damage repair (DDR) system by reducing DDR proteins while enhancing the killing of cancer cells by DDR-based therapeutics in vivo studies. In this single-center, multi-arm phase $1 \mathrm{~b}$ study, selinexor with carboplatin, doxorubicin and cyclophosphamide (DC), irinotecan with fluorouracil and folinic acid (FOLFIRI), irinotecan, and capecitabine and oxaliplatin (XELOX), were employed as separate parallel arms. Eligible patients have relapsed/ metastatic refractory solid tumors following standard therapy or addition of selinexor to systemic therapy was appropriate. Nineteen patients were treated in the 5 arms. Tumor types included were colorectal $(n=3)$, breast $(n=3)$, neuroendocrine $(n=2)$, ovarian $(n=2)$, and pancreas cancers $(n=2)$. All patients developed one treatment-related adverse events (TRAE). The most prevalent TRAE were thrombocytopenia (84\%), nausea (68\%), leukopenia (68\%), neutropenia (63\%), and fatigue (58\%). The common grade 3/4 TRAE were neutropenia (42\%), leukopenia (26\%), and hyponatremia (21\%). Three patients had dose-limiting toxicities (DLT) in 3 separate arms. Fourteen patients were evaluable for response. Although no patients achieved complete or partial response (CR or PR), seven patients attained stable disease (SD). Disease control rate (DCR) was 14\%. The combination of oral selinexor with different standard chemotherapies showed limited clinical activity despite toxicity and DLT prevented further dose escalation. Optimizing supportive care, the utility of growth factors, and aggressive measures on antiemetics strategies remain tangible.

Trial registration ClinicalTrials.gov Identifier: NCT02419495. Registered 14 April 2015, https://clinicaltrials.gov/ct2/show/ NCT02419495). Sponsor(s): Karyopharm Therapeutics
\end{abstract}

Keywords: Selinexor (KPT 330), Carboplatin, Irinotecan, FOLFIRI, Doxorubicin and cyclophosphamide, Capecitabine and oxaliplatin (XELOX)

\footnotetext{
*Correspondence: theink@ohsu.edu

${ }^{2}$ Division of Hematology and Medical Oncology, Oregon Health

and Science University/Knight Cancer Institute, 3181 SW Sam Jackson

Park Rd, Mail Code: OC 14HO, Portland, OR 97239, USA

Full list of author information is available at the end of the article
}

To the editor,

Selinexor (KPT-330) is an oral selective inhibitor of nuclear export (SINE) and was shown to hinder the DNA damage repair (DDR) system by diminishing DDR proteins expression while enhancing the killing of cancer cells by DDR-based therapeutics in vivo preclinical models [1-3]. Previous early phase studies demonstrated the modest activity of single agent selinexor in patients with permits use, sharing, adaptation, distribution and reproduction in any medium or format, as long as you give appropriate credit to the original author(s) and the source, provide a link to the Creative Commons licence, and indicate if changes were made. The images or other third party material in this article are included in the article's Creative Commons licence, unless indicated otherwise in a credit line to the material. If material is not included in the article's Creative Commons licence and your intended use is not permitted by statutory regulation or exceeds the permitted use, you will need to obtain permission directly from the copyright holder. To view a copy of this licence, visit http://creativecommons.org/licenses/by/4.0/. The Creative Commons Public Domain Dedication waiver (http://creativeco mmons.org/publicdomain/zero/1.0/) applies to the data made available in this article, unless otherwise stated in a credit line to the data. 
Table 1 Patients baseline demographics and disease characteristics

\begin{tabular}{|c|c|c|c|c|c|c|}
\hline Characteristic & $\begin{array}{l}\text { Selinexor } 60 \mathrm{mg} \\
\text { QW/BIW + } \\
\text { carboplatin 6 AUC } \\
\text { Q3W }(N=6)\end{array}$ & $\begin{array}{l}\text { Selinexor } 60 \mathrm{mg} \mathrm{QW/} \\
\text { BIW + doxorubicin } \\
60 \mathrm{mg} / \mathrm{m}^{2} \\
+ \text { cyclophosphamide } \\
600 \mathrm{mg} / \mathrm{m}^{2} \mathrm{Q} 3 \mathrm{~W} \\
(N=4)\end{array}$ & $\begin{array}{l}\text { Selinexor } 40 \mathrm{mg} \\
\mathrm{QW}+\mathrm{FOLFIR \textrm {a } ^ { \mathrm { a } }} \\
(N=3)\end{array}$ & $\begin{array}{l}\text { Selinexor } 60 \mathrm{mg} \\
\mathrm{QW}+\text { irinotecan } \\
125 \mathrm{mg} / \mathrm{m}^{2} \mathrm{D} 1 \\
\text { and } 8 \mathrm{Q} 3 \mathrm{~W}(\mathrm{~N} \\
=3)\end{array}$ & $\begin{array}{l}\text { Selinexor } 40 \mathrm{mg} \\
\mathrm{QW}+\mathrm{XELOX}^{\mathrm{b}} \\
(N=3)\end{array}$ & $\begin{array}{l}\text { All patients ( } N \\
=19)\end{array}$ \\
\hline \multicolumn{7}{|c|}{ Age at consent (years) } \\
\hline Median range & $56.1(31.2-76.1)$ & $61.7(23.6-64.9)$ & $49.9(38.1-70.7)$ & $67.8(57.9-72.3)$ & $65.9(51.8-72.8)$ & $60.6(23.6-76.1)$ \\
\hline \multicolumn{7}{|l|}{ Gender, N (\%) } \\
\hline Male & $1(17)$ & $2(50)$ & $1(33)$ & $1(33)$ & $2(67)$ & $7(37)$ \\
\hline Female & $5(83)$ & $2(50)$ & $2(67)$ & $2(67)$ & $1(33)$ & $12(63)$ \\
\hline \multicolumn{7}{|l|}{ Race/ethnicity, N (\%) } \\
\hline White & $4(67)$ & $4(100)$ & $3(100)$ & $1(33)$ & $3(100)$ & $15(79)$ \\
\hline Hispanic & 0 & 0 & 0 & 0 & 0 & 0 \\
\hline Black & $1(17)$ & 0 & 0 & $1(33)$ & 0 & $2(11)$ \\
\hline Asian & $1(17)$ & 0 & 0 & $1(33)$ & 0 & $2(11)$ \\
\hline \multicolumn{7}{|c|}{ ECOG performance status, $N(\%)$} \\
\hline 0 & $1(17)$ & 0 & $1(33)$ & $2(67)$ & $1(33)$ & $5(26)$ \\
\hline 1 & $5(83)$ & $4(100)$ & $2(67)$ & $1(33)$ & $2(67)$ & $14(74)$ \\
\hline \multicolumn{7}{|l|}{ Primary tumor, N (\%) } \\
\hline Ovarian & 0 & $2(50)$ & 0 & 0 & 0 & $2(11)$ \\
\hline Breast & $3(50)$ & 0 & 0 & 0 & 0 & $3(16)$ \\
\hline $\begin{array}{l}\text { Colorectal } \\
\text { cancer }\end{array}$ & 0 & 0 & 1 (33) & $1(33)$ & $1(33)$ & $3(16)$ \\
\hline $\begin{array}{l}\text { Endometrial/fal- } \\
\text { lopian }\end{array}$ & 0 & 0 & 0 & 0 & 0 & 0 \\
\hline Lung & $1(17)$ & 0 & 0 & 0 & 0 & $1(5)$ \\
\hline Neuroendocrine & 0 & 0 & $1(33)$ & $1(33)$ & 0 & $2(11)$ \\
\hline Pancreas & 0 & 0 & $1(33)$ & 0 & $1(33)$ & $2(11)$ \\
\hline Esophageal & 0 & 0 & 0 & 0 & 0 & 0 \\
\hline $\begin{array}{l}\text { Head and neck/ } \\
\text { salivary gland }\end{array}$ & $1(17)$ & 0 & 0 & $1(33)$ & 0 & $2(11)$ \\
\hline $\begin{array}{l}\text { Liver/cholangio- } \\
\text { carcinoma }\end{array}$ & 0 & 0 & 0 & 0 & $1(33)$ & $1(5)$ \\
\hline Sarcoma & 0 & $1(25)$ & 0 & 0 & 0 & $1(5)$ \\
\hline Prostate & 0 & $1(25)$ & 0 & 0 & 0 & $1(5)$ \\
\hline Others & $1(17)$ & 0 & 0 & 0 & 0 & $1(5)$ \\
\hline \multicolumn{7}{|c|}{ Prior lines of systemic therapies, $N(\%)$} \\
\hline $0-1$ & $1(17)$ & 0 & 0 & 0 & 0 & $1(5)$ \\
\hline $2-3$ & $4(67)$ & $3(75)$ & $2(67)$ & $2(67)$ & $2(67)$ & $13(68)$ \\
\hline $4-5$ & $1(17)$ & $1(25)$ & $1(33)$ & 0 & $1(33)$ & $4(21)$ \\
\hline$>5$ & 0 & 0 & 0 & $1(33)$ & 0 & $1(5)$ \\
\hline Median range & $2.5(1.0-4.0)$ & $2.0(2.0-4.0)$ & $3.0(3.0-5.0)$ & $3.0(2.0-6.0)$ & $3.0(2.0-4.0)$ & $3.0(1.0-6.0)$ \\
\hline
\end{tabular}

$N$ number; ECOG Eastern Cooperative Oncology Group; QW once weekly; BIW twice weekly; $A U C$ area under curve; $\mathrm{mg} / \mathrm{m}^{2} \mathrm{milligrams}$ per square meter; 1 and 8 on days 1, and 8 of each cycle; Q3W every 3 week; FOLFIRI irinotecan with fluorouracil and folinic acid; XELOX capecitabine and oxaliplatin

${ }^{\text {a }}$ FOLFIRI_irinotecan of $180 \mathrm{mg} / \mathrm{m}^{2}, 5$-FU continuous infusion of $2400 \mathrm{mg} / \mathrm{m}^{2}, 5$-FU bolus of $400 \mathrm{mg} / \mathrm{m}^{2}$, and leucovorin of $400 \mathrm{mg} / \mathrm{m}^{2}$ on days 1 , and 15

${ }^{\mathrm{b}}$ XELOX_capecitabine was dosed at $900 \mathrm{mg} / \mathrm{m}^{2}$ orally (PO) divided into 2 doses on days $1-14$, along with oxaliplatin of $130 \mathrm{mg} / \mathrm{m}^{2} \mathrm{IV}$ Q3W 


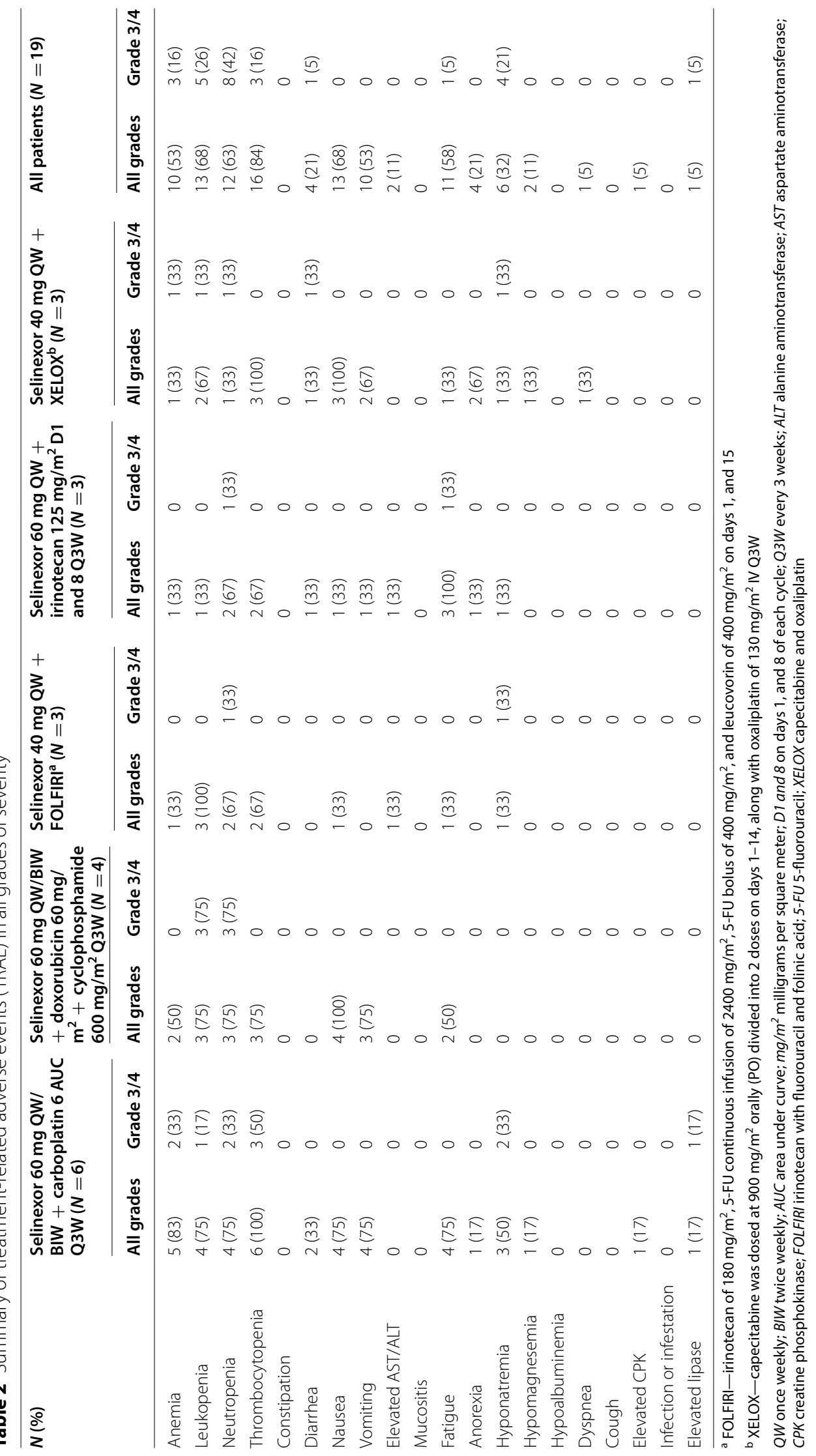


solid tumors [4-6]. In vivo studies of selinexor in combination with different chemotherapeutics demonstrated synergistic activity $[3,7,8]$. An open-label, multi-arm phase $1 \mathrm{~b}$ study utilizing selinexor in combination with different standard chemotherapies was conducted at MD Anderson Cancer Center to evaluate the safety and tolerability of the combination. Herein, we report results from 5 closed separate arms of the study.

Eligible patients were adult (age $\geq 18$ years) patients with histologically documented, relapsed/metastatic refractory solid tumors following standard therapy or adding selinexor to systemic therapy was appropriate. The primary aim was to evaluate the safety and tolerability of selinexor when given in combination with different standard chemotherapies and the secondary aim was to determine the preliminary antitumor activity [DCR $(\mathrm{CR}+\mathrm{PR}+\mathrm{SD} \geq 6$ months), and progression-free survival (PFS)].

Nineteen patients with relapsed/refractory solid tumors were enrolled between July 2015 and January 2017. The demographic and clinical characteristics of all patients enrolled are summarized in Table 1 . No patients are currently in the study where the majority of patients withdrew from the study due to progression of disease while 5 patients withdrew due to clinically intolerable treatment-emergent adverse events (TEAE). All patients experienced at least one TEAE and TRAE (Table 2 and Additional file 1: Table S2). The commonest TRAE were thrombocytopenia (84\%), nausea $(68 \%)$, leukopenia (68\%), neutropenia (63\%), fatigue (58\%), vomiting (53\%), and anemia (53\%). The most prevalent grade 3/4 TRAE were neutropenia (42\%), leukopenia (26\%), hyponatremia (21\%), anemia (16\%), and thrombocytopenia (16\%). Three patients experienced DLTs; a patient dosed at selinexor $60 \mathrm{mg}$ twice weekly (BIW) with DC reported grade 3 leukopenia and grade 4 neutropenia; a patient receiving selinexor at $40 \mathrm{mg}$ once weekly (QW) with FOLFIRI reported grade 3 febrile neutropenia (FN); and a patient receiving selinexor at $40 \mathrm{mg}$ QW with XELOX reported grade 3 diarrhea. Four patients were reported to have serious adverse events (SAEs). One patient receiving selinexor with DC had an SAE from treatment-related grade $3 \mathrm{FN}$. Two patients in the combination of selinexor with FOLFIRI had SAEs; one patient had treatmentrelated grade $3 \mathrm{FN}$ while the other had treatment-unrelated grade 2 pancreatitis. One patient receiving selinexor with XELOX had an SAE from treatment-related grade 3 diarrhea and treatment-unrelated grade 3 dyspnea and skin infection. No patients died during the study.

All patients enrolled had measurable disease, but 5 patients had not completed their first restaging scans due to earlier withdrawal of consent and toxicity. Fourteen patients were considered efficacy evaluable patients
(Additional file 1: Figure S1). No patients had objective responses, however, 7 patients had SD. Of the $7 \mathrm{SD}$ patients, 2 received selinexor with DC (ovarian cancer), 2 received selinexor with FOLFIRI [colorectal cancer (CRC); neuroendocrine carcinoma of the pancreas], 2 received selinexor with XELOX (CRC; cholangiocarcinoma), and 1 received selinexor with irinotecan (CRC). All had progressed on multiple prior lines of therapy including FOLFOX, FOLFIRI, cisplatin + gemcitabine, FOLFRINOX, temozolomide, everolimus, octreotide, capecitabine, sunitinib, and ziv-aflibercept. The median time-to-treatment failure (TTF) was 20 weeks (range, 6-29 weeks). Two patients who received selinexor with XELOX experienced disease control resulting in a DCR of $14 \%$. A patient with CRC who progressed on prior 4 lines of therapies, had stable disease with TTF of 26 weeks. Another patient with cholangiocarcinoma who progressed on prior 3 lines of therapies including cisplatin + gemcitabine, FOLFRINOX, had stable disease with TTF of 29 weeks. The median PFS for all patients was 2.0 months $(95 \%$ CI 1.2, 2.8) while the median OS for all patients was 5.2 months $(95 \%$ CI 4.0,11.2) (Additional file 1: Figure S2).

In conclusion, selinexor in combination with standard chemotherapy showed limited clinical activity with some toxicity. Although RP2D of selinexor was $40 \mathrm{mg}$ QW in combination with XELOX or FOLFIRI, the study arms were not pursued for dose expansion due to toxicities and lack of response. Optimizing supportive care, proper use of growth factors, and aggressive measures on antiemetics strategies are important to mitigate TRAE.

\section{Supplementary Information}

The online version contains supplementary material available at https://doi. org/10.1186/s40164-021-00251-0.

Additional file 1: Table S1. Summary of treatment-emergent adverse events in the phase I safety population. Table S2. Summary of treatmentemergent adverse events (TEAE) in all grades of severity. Figure S1. Waterfall plot of maximum change in tumor measurements (per RECIST v1.1) for evaluable patients. Figure S2. Kaplan-Meier plot showing progressionfree survival (PFS) and overall survival (OS) for all treated patients.

\section{Acknowledgements}

We thank the patients who participated in this study, and their families for supporting them.

\section{Authors' contributions}

All the authors have contributed to the preparation of this manuscript. All authors read and approved the final manuscript.

\section{Funding}

Karyopharm Therapeutics, Clinical and Translational Sciences Award (1UL1TR003167) (NIH/NCATS), and MD Anderson Cancer Support Grant (P30CA016672) (NIH-NCI). 


\section{Availability of data and materials}

The datasets used and/or analyzed during the current study are available from the corresponding author on reasonable request.

\section{Code availability}

Not applicable.

\section{Declarations}

Ethics approval and consent to participate

The study protocol was approved by the Institutional Review Board or Independent Ethics Committee at MD Anderson Cancer Center and was conducted in accordance with the Declaration of Helsinki, Good Clinical Practice, and all local and federal regulatory guidelines (obtained).

\section{Consent for publication}

Applicable (obtained). Informed consent was obtained from all individual participants included in the study (obtained).

\section{Competing interests}

Apostolia-Maria Tsimberidou has the following financial relationships to disclose: Research Funding (Institution): Immatics, Parker Institute for Cancer Immunotherapy, Tempus, OBI Pharma, EMD Serono, Baxalta, ONYX, Bayer, Boston Biomedical, Placon Therapeutics, Karus Therapeutics, and Tvardi Therapeutics. Consulting or Advisory Role: Covance, Genentech and Tempus. Aung Naing reports research funding from NCl; EMD Serono; Medlmmune; Healios Onc. Nutrition; Atterocor; Amplimmune; ARMO BioSciences; Eli Lilly; Karyopharm Therapeutics; Incyte; Novartis; Regeneron; Merck; BMS; Pfizer, CytomX Therapeutics; Neon Therapeutics; Calithera Biosciences; TopAlliance Biosciences; Kymab; PsiOxus; Arcus Biosciences; NeoimmuneTech; ImmuneOncia; Surface Oncology. On advisory board of CytomX Therapeutics; Novartis and Genome \& Company; OncoSec KEYNOTE-695; STCube. Travel and accommodation expense from ARMO BioSciences. Spouse Research funding: Immune Deficiency Foundation, Jeffery Modell Foundation and chao physician-scientist, and Baxalta. Advisory board: Takeda, CSL, Behring, Horizon, and Pharming. David S. Hong reports Research/Grant Funding: AbbVie, Adaptimmune, Aldi-Norte, Amgen, Astra Zeneca, Bayer, Bristol-Myers Squibb, Daiichi-Sankyo, Eisai, Fate Therapeutics, Genentech, Genmab, GlaxoSmithKline, Ignyta, Infinity, Kite, Kyowa, Lilly, LOXO, Merck, Medlmmune, Mirati, miRNA, Molecular Templates, Mologen, NCl-CTEP, Novartis, Pfizer, Seattle Genetics, Takeda, Turning Point Therapeutics. Travel, Accommodations, Expenses: Bayer, Genmab, AACR, ASCO, P.O.E.T, CCLO, SITC. Consulting or Advisory Role: Alpha Insights, Amgen, Axiom, Adaptimmune, Baxter, Bayer, eCancer, Genentech, GLG, Group H, Guidepoint, Infinity, Liberium, Medscape, Numab, Oncology Education Project Association, Pfizer, Prime Oncology, Takeda, Trieza, Therapeutics, WebMD. Other ownership interests: Molecular Match (Advisor), OncoResponse (Founder), Presagia Inc. (Advisor). Filip Janku reports Grant/Research Funding (Institutional): Novartis, Genentech, BioMed Valley Discoveries, Plexxikon, Deciphera, Piqur, Symphogen, Bayer, FujiFilm Corporation and Upsher-Smith Laboratories, Astex, Asana, Astellas, Agios, Proximagen, Bristol-Myers Squibb. Scientific Advisory Board: Deciphera, IFM Therapeutics, Synlogic, Guardant Health, Ideaya, PureTech Health. Paid Consultant: Trovagene, Immunomet, Jazz Pharmaceuticals, Sotio. Ownership Interests: Trovagene. Funda Meric-Bernstam reports Consulting: Aduro BioTech Inc., Alkermes, AstraZeneca, DebioPharm, eFFECTOR Therapeutics, F. HoffmanLa Roche Ltd., Genentech Inc., IBM Watson, Jackson Laboratory, Kolon Life Science, OrigiMed, PACT Pharma, Parexel International, Pfizer Inc., Samsung Bioepis, Seattle Genetics Inc., Tyra Biosciences, Xencor, Zymeworks. Advisory Committee: Immunomedics, Inflection Biosciences, Mersana Therapeutics, Puma Biotechnology Inc., Seattle Genetics, Silverback Therapeutics, Spectrum Pharmaceuticals, Zentalis. Sponsored Research: Aileron Therapeutics, Inc. AstraZeneca, Bayer Healthcare Pharmaceutical, Calithera Biosciences Inc., Curis Inc., CytomX Therapeutics Inc., Daiichi Sankyo Co. Ltd., Debiopharm International, eFFECTOR Therapeutics, Genentech Inc., Guardant Health Inc., Millennium Pharmaceuticals Inc., Novartis, Puma Biotechnology Inc., Taiho Pharmaceutical Co. Honoraria: Chugai Biopharmaceuticals, Mayo Clinic, Rutgers Cancer Institute of New Jersey. Other (Travel Related): Beth Israel Deaconess Medical Center. Sarina A. Piha-Paul receives Research/ Grant Funding through the institution from the following sources: AbbVie,
Inc.; ABM Therapeutics, Inc.; Acepodia, Inc.; Alkermes; Aminex Therapeutics; Amphivena Therapeutics, Inc.; BioMarin Pharmaceutical, Inc.; Boehringer Ingelheim; Bristol Myers Squib; Cerulean Pharma, Inc.; Chugai Pharmaceutical Co., Ltd.; Curis, Inc.; Daiichi Sankyo; Eli Lilly; ENB Therapeutics; Five Prime Therapeutics; Gene Quantum; Genmab A/S; GlaxoSmithKline; Helix BioPharma Corp.; Incyte Corp.; Jacobio Pharmaceuticals Co., Ltd.; Medimmune, LLC.; Medivation, Inc.; Merck Sharp and Dohme Corp.; Novartis Pharmaceuticals; Pieris Pharmaceuticals, Inc.; Pfizer; Principia Biopharma, Inc.; Puma Biotechnology, Inc.; Rapt Therapeutics, Inc.; Seattle Genetics; Silverback Therapeutics; Taiho Oncology; Tesaro, Inc.; TransThera Bio; NCl/ $\mathrm{NIH}$; P30CA016672-Core Grant (CCSG Shared Resources). Siqing Fu reports clinical trial research funding paid to the institution from Eli Lilly, during the conduct of the study; and clinical trial research funding paid to the institution from AstraZeneca, Abbisko, Anaeropharma Science, Arrien Pharmaceuticals, BeiGene, BioAtla, LLC, Boehringer Ingelheim, Eli Lilly, Hookipa Biotech GmBH, Huya Bioscience International, IMV, Inc., Innovent Biologics, Co., Ltd., Lyvgen Biopharm, Co., Ltd., MacroGenics, Medivir AB, Millennium Pharmaceuticals, Inc., Nerviano Medical Sciences, NeuPharma, Inc., NIH/NCl, Novartis, OncoMed, Parexel International, LLC, Sellas Life Sciences Group, Soricimed Biopharma, Inc., Tolero Pharmaceuticals, all outside the submitted work. Vivek Subbiah reports research funding/Grant support for clinical trials: Roche/Genentech, Novartis, Bayer, GlaxoSmithKline, Nanocarrier, Vegenics, Celgene, Northwest Biotherapeutics, Berghealth, Incyte, Fujifilm, Pharmamar, D3, Pfizer, Multivir, Amgen, Abbvie, Alfa-sigma, Agensys, Boston Biomedical, Idera Pharma, Inhibrx, Exelixis, Blueprint medicines, Loxo oncology, Medimmune, Altum, Dragonfly. therapeutics, Takeda and, National Comprehensive Cancer Network, NCI-CTEP and UT MD Anderson Cancer Center, Turning point therapeutics, Boston Pharmaceuticals; Travel: Novartis, Pharmamar, ASCO, ESMO, Helsinn, Incyte; Consultancy/Advisory board: Helsinn, LOXO Oncology/Eli Lilly, R-Pharma US, INCYTE, QED pharma, Medimmune, Novartis. Other: Medscape. Timothy A. Yap reports research support (to institution) from Artios, AstraZeneca, Bayer, Clovis, Constellation, Cyteir, Eli Lilly, EMD Serono, Forbius, F-Star, GlaxoSmithKline, Genentech, ImmuneSensor, Ipsen, Jounce, Karyopharm, Kyowa, Merck, Novartis, Pfizer, Ribon Therapeutics, Regeneron, Repare, Sanofi, Scholar Rock, Seattle Genetics, Tesaro, and Vertex Pharmaceuticals, and consultancy fees from Almac, Aduro, AstraZeneca, Atrin, Axiom, Bayer, Bristol-Myers Squibb, Calithera, Clovis, Cybrexa, EMD Serono, F-Star, Guidepoint, Ignyta, I-Mab, Janssen, Merck, Pfizer, Repare, Roche, Rubius, Schrodinger, Seattle Genetics, Varian and Zai Labs outside of the submitted work. Jatin Shah is an employee of and stockholder of Karyopharm. All remaining authors have declared no competing interests.

\section{Research involving human participants and/or animals}

This study was conducted in accordance with the US Common Rule.

\section{Author details}

${ }^{1}$ Department of Investigational Cancer Therapeutics, The University of Texas MD Anderson Cancer Center, Houston, TX, USA. ${ }^{2}$ Division of Hematology and Medical Oncology, Oregon Health and Science University/Knight Cancer Institute, 3181 SW Sam Jackson Park Rd, Mail Code: OC14HO, Portland, OR 97239, USA. ${ }^{3}$ Karyopharm Therapeutics, Newton, MA, USA. ${ }^{4}$ Department of Biostatistics, The University of Texas MD Anderson Cancer Center, Houston, TX, USA. ${ }^{5}$ Department of Thoracic Imaging, Division of Diagnostic Imaging, The University of Texas MD Anderson Cancer Center, Houston, TX, USA. ${ }^{6}$ Department of Diagnostic Radiology, The University of Texas MD Anderson Cancer Center, Houston, TX, USA.

Received: 2 October 2021 Accepted: 18 December 2021 Published online: 29 December 2021

\section{References}

1. Fung HY, Chook YM. Atomic basis of CRM1-cargo recognition, release and inhibition. Semin Cancer Biol. 2014;27:52-61.

2. Senapedis WT, Baloglu E, Landesman Y. Clinical translation of nuclear export inhibitors in cancer. Semin Cancer Biol. 2014;27:74-86.

3. Kashyap T, Argueta C, Unger T, Klebanov B, Debler S, Senapedis W, et al. Selinexor reduces the expression of DNA damage repair proteins 
and sensitizes cancer cells to DNA damaging agents. Oncotarget. 2018;9(56):30773-86.

4. Shafique $M$, Ismail-Khan R, Extermann M, Sullivan $D$, Goodridge $D$, Boulware D, et al. A phase II trial of selinexor (KPT-330) for metastatic triple-negative breast cancer. Oncologist. 2019;24(7):887-e416.

5. Vergote IB, Lund B, Peen U, Umajuridze Z, Mau-Sorensen M, Kranich $A$, et al. Phase 2 study of the Exportin 1 inhibitor selinexor in patients with recurrent gynecological malignancies. Gynecol Oncol. 2020:156(2):308-14.

6. Gounder MM, Zer A, Tap WD, Salah S, Dickson MA, Gupta AA, et al. Phase IB study of selinexor, a first-in-class inhibitor of nuclear export, in patients with advanced refractory bone or soft tissue sarcoma. J Clin Oncol. 2016;34(26):3166-74.

7. Baek HB, Lombard AP, Libertini SJ, Fernandez-Rubio A, Vinall R, Gandour-Edwards R, et al. XPO1 inhibition by selinexor induces potent cytotoxicity against high grade bladder malignancies. Oncotarget. 2018;9(77):34567-81.

8. Arango NP, Yuca E, Zhao M, Evans KW, Scott S, Kim C, et al. Selinexor (KPT-330) demonstrates anti-tumor efficacy in preclinical models of triple-negative breast cancer. Breast Cancer Res. 2017;19(1):93.

\section{Publisher's Note}

Springer Nature remains neutral with regard to jurisdictional claims in published maps and institutional affiliations.

- fast, convenient online submission

- thorough peer review by experienced researchers in your field

- rapid publication on acceptance

- support for research data, including large and complex data types

- gold Open Access which fosters wider collaboration and increased citations

- maximum visibility for your research: over $100 \mathrm{M}$ website views per year

At BMC, research is always in progress.

Learn more biomedcentral.com/submissions 